\title{
Os Udis: uma língua, uma religião e uma etnografia
}

\author{
Robert Baqratovic Mobili ( $\left.{ }^{*}\right)$
}

BAQRATOVIC MOBILI, R. Os Udis: uma língua, uma religião e uma etnografia. R. Museu Arq. Etn., 24: 163-179, 2014.

Resumo: Este artigo apresenta a história e a etnografia do povo udi-albanês, minoria étnica do Azerbaijão e uma das mais antigas culturas da humanidade com história contínua. Remanescentes do antigo Reino da Albânia do Cáucaso, conservaram a língua nativa, costumes e o cristianismo em meio ao milenar domínio islâmico. Atualmente tem representatividade junto ao governo da República do Azerbaijão e encontra-se em pleno processo de renascimento cultural e desenvolvimento econômico. Fruto de diligentes pesquisas nas áreas da antropologia cultural, história documentada e oral, o autor apresenta relevantes resultados no campo da linguística, história e etnografia do povo udi.

Palavras-chave: Etnografia; Azerbaijão; Udi-albaneses; Albânia do Cáucaso; História; Linguística; Nij; Cristianismo; História da Igreja.

$\mathrm{O}$ desenvolvimento e a formação do povo azerbaijano é o resultado de um processo de longa duração que não pôde acontecer senão pela ação de contatos e misturas entre diversas tribos e etnias. No total, no Azerbaijão vinte minorias nacionais coabitam com a etnia principal. Juntos constituem um povo multinacional unificado, o do Azerbaijão. Entre essas minorias do tronco de uma etnia, os udis têm uma origem e uma história que atraem a atenção e suscitam há quase dois séculos o interesse do mundo científico. São autóctones do Azerbaijão e um dos povos mais antigos do Cáucaso. (fig. 1)

(*) Baku State University. Azerbaijão. Departamento de Mineralogia, Cristalografia e Geoquímica.<argomobili@ rambler.ru>
A conjunção dos esforços dos historiadores, linguistas e etnógrafos, da qual este texto é um exemplo, apresenta uma estratégia extraordinariamente importante na medida em que nos últimos decênios se intensificou a migração dos udis para fora de seu território tradicional de povoamento, assim como o processo de assimilação dos mesmos em sua diáspora. Observa-se uma baixa constante do número dos falantes da língua udi. Eis porque importantes projetos estão sendo implementados, não apenas o de uma apresentação científica da situação linguística e etnográfica dos udis de hoje, mas também a criação de um documento no que diz respeito às particularidades linguística e etnográfica que se conservaram e se transmitiram (as obras de arte popular, textos etnográficos, fotografias, gravações em áudio e vídeos). Os udis faziam 


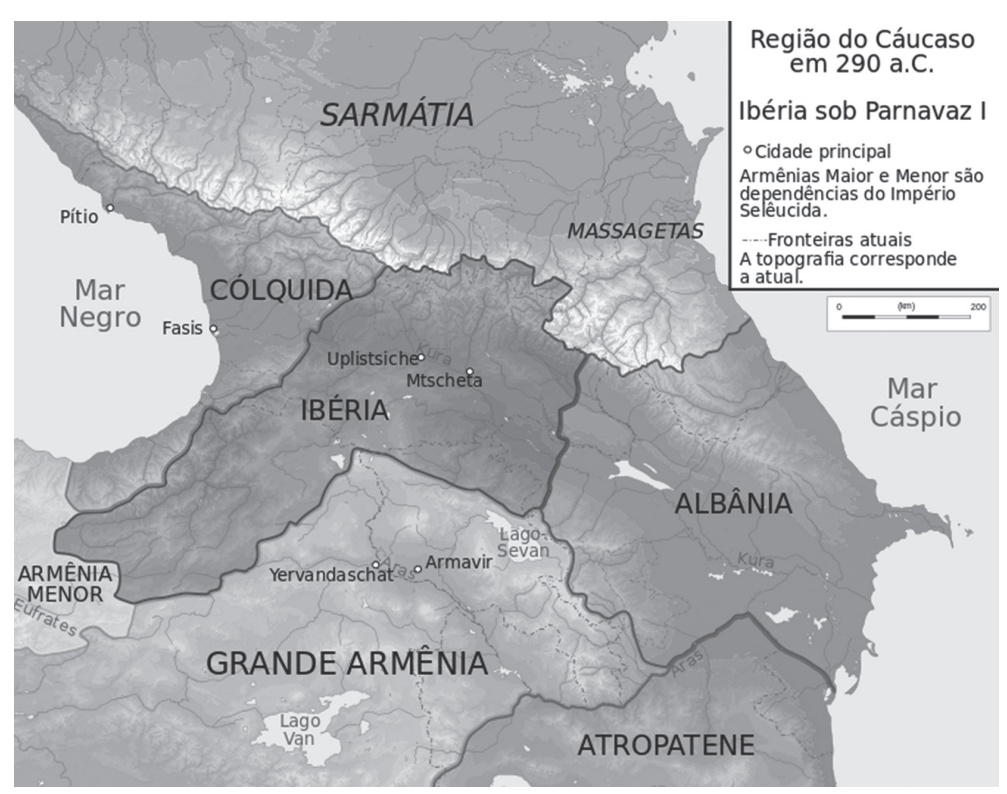

Fig. 1. Mapa da antiga Albânia do Cáucaso. Fonte: http://pt.wikipedia.org/ wiki/Ficheiro:Caucasus_290_BC_map_pt.svg

parte das vinte e seis tribos albanesas que criaram o Reino da Albânia Caucasiana (século III a. C. ao século VII d.C.) e são antepassados dos povos azerbaijanos modernos. Desde então foram editados trezentos trabalhos sobre a antropologia (Arutinov 1905: 93-94), língua (Gukasyan 1974: 3-34), religião (Huseynov 2008: 22-25), filologia (Gukasyan 1974: 17-19; Ganenkov 2008: 3-77), etnografia (Bezhanov 1892: 219-260; Javadov; Huseynov 1999: 199 . 228), história (Javadov; Huseynov 1999: 18-86), origens (Melikov 2002: 78-81), cultura (Javadov; Huseynov 1999: 87-95), tradições e costumes (Kechaari 2001: 3; Mobili: 26, 29) dos udi-albaneses. Os dados acumulados testemunham formalmente que os udis são os mais antigos habitantes do Cáucaso assinalados no espaço histórico-cultural do Azerbaijão. (fig. 2)

Heródoto, o Pai da História, pela primeira vez há 2.500 anos faz menção aos antepassados do grupo udi quando relata a batalha de Maratona (Herodotus1987: Book III, Chapter 93 e Book VII). Nas fontes mais antigas, os udis são designados como um dos protagonistas tendo participado da batalha de Alexandre Magno contra os persas das tropas do sátrapa dos medos em Gaugamela (331 a.C). São igualmen- te mencionados na "Geografia" de Estrabão, quando descreve o Mar Cáspio e a Albânia caucasiana (Strabo 1924: Book XI, 4. 501-503). O étimo udi aparece pela primeira vez na História Natural de Plínio, o Velho, autor romano do século I d.C (Pliny the Elder 1855: Book III - VI) . Posteriormente aparece na Geografia de Ptolomeu, escritor helênico do século II d.C., na qual diz que "à beira do Mar Cáspio vivem diversas tribos, dentre elas, a dos udis" (Claudii Ptolemaei 1883: Liber V-VII).

Encontram-se testemunhos mais precisos sobre os udis na "História do País de Aluank" do autor local Moisés Kalankatuatsi (em udi: kala: grande; katu: povoamento) o qual viveu no século VII e, segundo suas próprias palavras, pertenceu ao clã dos udis e evoca o fundador mítico das tribos albanesas ao personagem bíblico Aran: "De [seu] filho, nasceram as tribos dos udi, dos gardman, dos tsavdeysk e dos gargar" (Movsēs Dasxuranc'i 1961). A história do reino albanês é bem conhecida atualmente e ele foi um dos que subsistiram por mais tempo no Cáucaso - mais de mil anos - e compreendia o atual norte do Azerbaijão e o sul do Daguestão até o Rio Suluk, englobando os territórios da Kakhétie-Héréthie na Georgia 
e o Zangezur no sul de Karabakh. Todas estas terras representavam onze das antigas províncias albanesas: Tchola, Lpiniya, Kambisena, Edjeri, Gabala, Shaki, Paytarakan (Partav), Gardman, Artsakh, Sunik e Uti. A língua oficial do Estado Albanês, como afirmam os especialistas, era o antigo udi. A província de Udi, povoada pelos udis, era conhecida dos autores da Grécia antiga como Otena. Ocupava o território que vai do Mar Cáspio, passando pelo maciço principal da cadeia do Cáucaso, até o Rio Alazan.

Até o início do século XX, os udis viveram reagrupados nas aldeias de $\mathrm{Nij}$, Vartashen (Oghuz), Mirzabeyli, Vardanli (Kerimli) Sultan -nukha, JorluYakublu, Malikh, Yenikend, Talish e Kirzan. As mais antigas informações sobre a população udi moderna remontam ao último quarto do século XIX: em 1880, no Império Russo, contavam-se dez mil, mas no fim do século não passavam além de oito mil, dos quais cinco mil em Nij e três mil em Vartashen. Em 1910, o número deles eleva-se já para os cinco

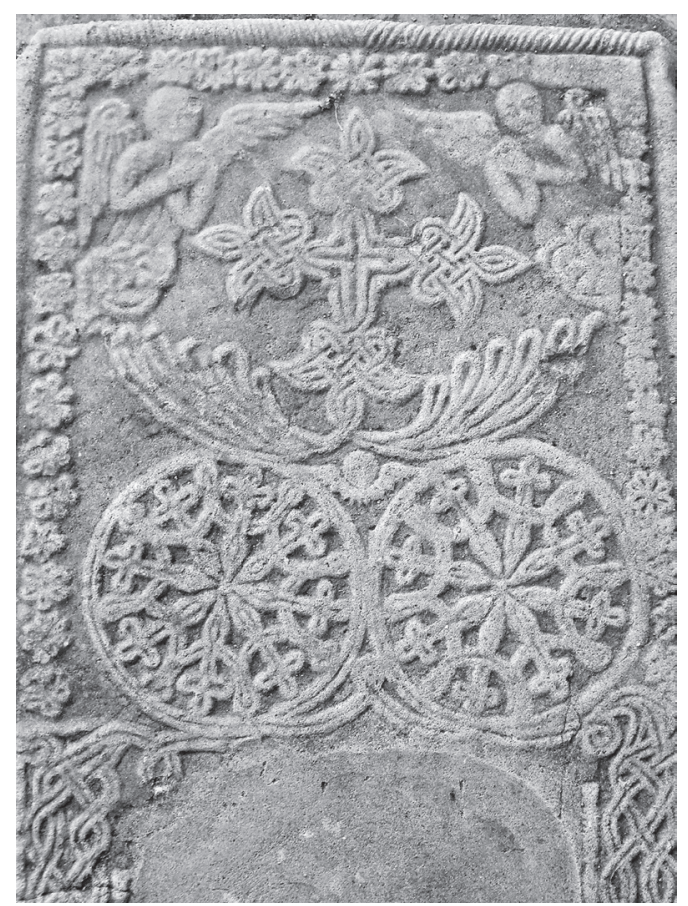

Fig. 2. Lápide sobre o túmulo de um sacerdote (final do século XVII). Entrada sul da Igreja de Santo Eliseu em Nij. Azerbaijão. Foto do autor, 2014. mil e novecentos, mas segundo o recenseamento geral de 1989, a população mundial dos udis foi avaliada em oito mil seiscentos e dez, dos quais seis mil cento e vinte e cinco no Azerbaijão. Atualmente, o número total dos udis é de mais de seis mil, do qual o efetivo principal - perto de quatro mil - vive no Azerbaijão, essencialmente reagrupado em $\mathrm{Nij}$ e de maneira mais esporádica em Oghuz e em Baku. Nij é uma das maiores zonas de povoamento udi da região de Gabala, localizada ao sudoeste da cidade do mesmo nome que é o centro, sendo um lugar único se estendendo por mais de cem quilômetros quadrados, onde vivem de maneira mais densa os udis, que ao lado dos azerbaijanos e dos lezguins (um povo que vive ao sul do Daguestão), não perderam sua especificidade etnocultural. Situa-se em uma planície plantada de aveleiras, nogueiras e castanheiras, ocupando uma grande extensão ao pé do vertente sul do grande Cáucaso, com terras cultivadas, construções de sólidas casas, cercadas de grandes hortas e pomares de árvores frutíferas. (figs. 3 e 4)

Um pequeno grupo dos udis vive na Geórgia, no povoado de Oktomberi (Zinobiani) da região de Kvareli. O resto dos udis vive esporadicamente em algumas grandes cidades da Rússia (Moscou, São Petersburgo, Volgograd, Astrakhan, Ekaterinbourgo, Ivanovo etc.) e nas zonas de povoamento da região de Krasnodar, Rostov sobre Don, Volgogrado, Kalouga, Tver e muitas outras. Enfim os encontramos de maneira relativamente reagrupada nas cidades de Shakhta e de Taganrog da região de Rostov. Uma pequena diáspora udi constituída de cerca de setecentas ou oitocentas pessoas vivem no Kazaquistão em Aktau e na Ucrânia em Gorlovka. Alguns udis vivem igualmente de maneira dispersa na França, Estados Unidos, Bielorrússia, Letônia e Ucrânia, assim como em outros países da CEI (Comunidade dos Estados Independentes. Uma organização supranacional envolvendo 11 repúblicas que pertenciam à antiga União Soviética). Segundo os dados do recenseamento de 2002, haveria na Rússia três mil setecentos e vinte e um udis. Estes números foram minimizados porque os udis foram obrigados a deixar suas regiões de povoamento histórico no decorrer do século XX e especifi- 
camente após o início da Perestróica e após a queda da União Soviética.

O acontecimento mais importante da atualidade na vida dos udis foi o encontro cordial e respeitoso dos habitantes de Nij, cuja história é mais de duas vezes milenar, com o presidente do Azerbaijão, Ilham Aliyev e sua esposa Mehriban Aliyeva, em 18 de agosto de 2005 (fig. 5). Ilham Aliyev pronunciou um discurso diante dos habi-

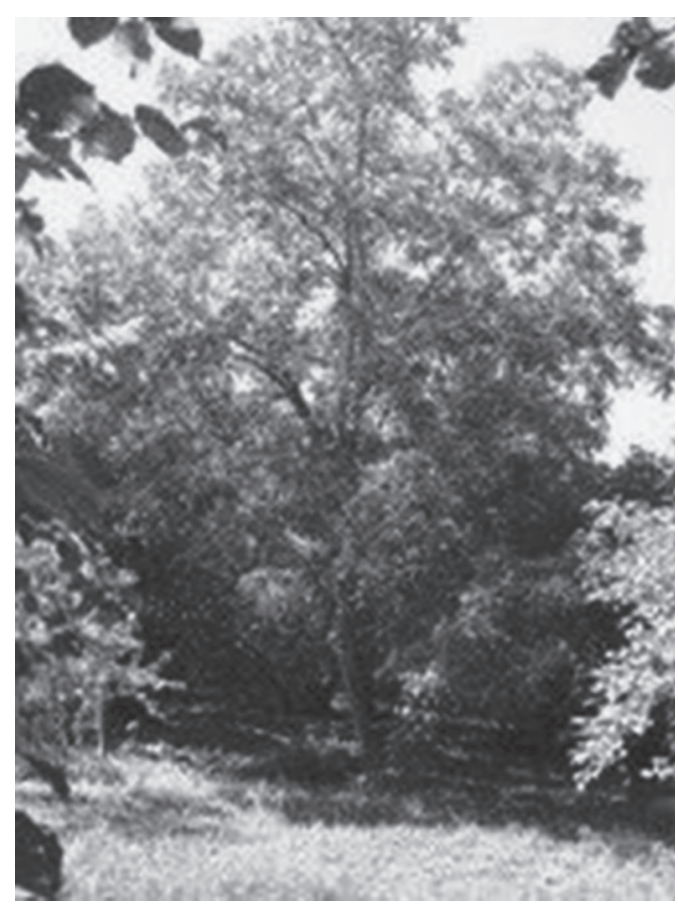

Fig. 3. Bosques de nogueiras e aveleiras na região de Nij. Foto do autor, 2012.

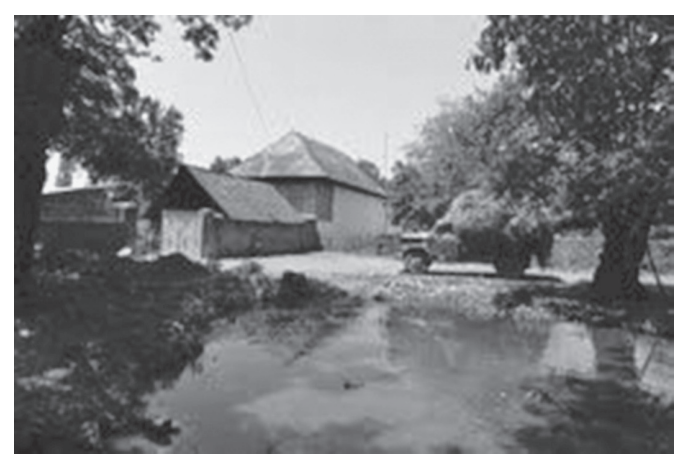

Fig. 4. Casa no vilarejo de Nij, região Gabala. Azerbaijão, 2012. Foto do autor. tantes do lugarejo. As comunidades étnicas da República do Azerbaijão possuem suas próprias organizações religiosas e sociais ocupando-se dos problemas espirituais de seus membros, que recebem apoio do Estado. O registro da comunidade udi-albanesa cristã pelo Comitê Estatal Azerbaijano para as Comunidades Religiosas, no dia 10 de abril de 2003, assumiu um imenso significado espiritual para o povo udi. Em 19 de maio de 2006 realizou-se a cerimônia inaugural e a cerimônias de consagração da igreja udi-albanesa de Santo Eliseu de Tchotari, restaurada em Nij. Ocasião em que foi anunciado que daí em diante seria sempre festejado o dia 19 de maio como o dia do Renascimento da Igreja Albanesa do Azerbaijão. A conservação da língua, da cultura e da herança espiritual udi é considerada como uma pequena, mas irrefutável, parte da história do Azerbaijão, é a missão fixada pelo Centro Nacional para a Cultura e a Civilização "Orayin" e a comunidade cristã udi-albanesa. Promovendo o conhecimento da história e da Cultura udi, preparam a edição de obras literárias e pedagógicas em língua udi e a publicação de coletâneas do folclore e de relatos de autores udis; enfim, mantém laços com os udis do Azerbadjão e os da diáspora udi que vivem fora do território de sua pátria histórica.

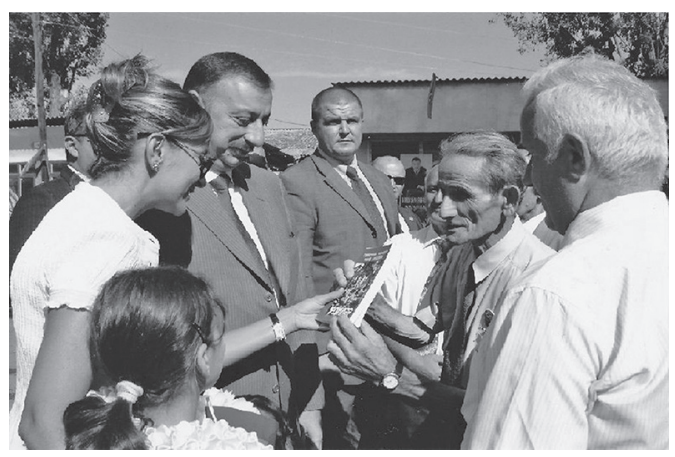

Fig. 5. Visita oficial do Presidente da República do Azerbaijão a Nij, um dos principais núcleos urbanos da população udi, em 18 de agosto de 2005. Foto: Azərbaycan Xəbər Agentliyi [Agência de Notícias do Azerbaijão]. 


\section{A língua}

A língua contemporânea udi faz parte das línguas ágrafas pertencentes ao subgrupo lezguins, incluído do grupo nakhdaguestanas da família das línguas ibérico-caucasianas e conta com dois dialetos: $\mathrm{O}$ nidzhien e o oghuzien- oktombérique (espalhado na região de Oghuz e de Oktomberi na Geórgia). O primeiro dialeto se subdivide em três variantes que correspondem a três zonas territoriais: a baixa, a intermediária e a alta. Estas variantes representavam historicamente falas distintas (mas pode-se também criar a hipótese de que elas foram, em um dado momento, dialetos diferentes da língua udi). Após o reagrupamento e a instalação dos udis na aldeia de Nij, estas variantes foram unificadas e fundidas ao dialeto de Nij. Ao dialeto de Vartashen (que se tornou em seguida o dialeto oghuzien-oktombérique) se une a linguagem de Oktomberi (Zinobiani). Os udis migraram de Vartashen (Oghuz) a Oktomberi em 1920, eis porque no seu modo de falar não há particularidades que o diferenciem substancialmente do dialeto udi do distrito de Oghuz. No decorrer dos últimos cem anos, os dialetos da língua udi se desenvolveram de maneira independente, e eis porque abundam neles as palavras provenientes de outras línguas. Assim constatamos um conjunto bem caracterizado de particularidades fonéticas, morfológicas e lexicais, cujas origens mergulham nas profundezas de um passado muito longínquo e opõem estes dialetos uns aos outros.

Todos os udis falam a língua materna, e dominam perfeitamente o azerbaijano e o russo. A língua udi é a língua dos descendentes daqueles que falavam a língua da Albânia Caucasiana. Distingue-se de outras línguas caucasianas foneticamente pela presença de um consonantismo mais simples, e gramaticalmente pela ausência de classes gramaticais, e a presença de prefixos e sufixos antigos, e enfim pela presença de bases substantivas e verbais irregulares. Na língua udi, a formação de substantivo é muito ativa. Sua originalidade consiste no fato de que ela é a herdeira direta da antiga língua escrita da Albânia do Cáucaso remontando ao primeiro milênio de nossa era. Conserva os sufixos arcaicos da pluralidade, os princípios da categoria da voz e a forma do acusativo. No dialeto de $\mathrm{Nij}$, existem quinze fonemas vocálicos. Não tem variantes longas ou breves, somente uma duração média. As vogais longas se formam durante o contato de duas vogais, mas não têm por isso fonemas independentes, posto que este fonema esteja estreitamente ligado à queda das consoantes.

Com a conversão da Albânia Caucasiana ao cristianismo foi criada a escrita albanesa, utilizada do século $\mathrm{V}$ ao século IX pela igreja cristã local. $\mathrm{O}$ alfabeto continha cinquenta e dois grafemas. A tradição histórica testemunha a existência, no passado, de um conjunto de grandes obras da literatura aghvan (termo relativo a Aghbania, antigo nome local da Albânia do Cáucaso) destruídas na Idade Média; o patrimônio epigráfico da escritura albanesa conservado e conhecido é muito pobre. Desvendamos certos empréstimos das línguas persa, georgiana, árabe, grega, russa e siríaca. No entanto, a influência dominante sobre o léxico udi é da língua azeri (turco-azerbaijana). No século XIX, os udis obtiveram a possibilidade de se iniciar à cultura escrita moderna. Em 1854, foi aberta uma primeira escola udi e em seguida uma escola aldeã com o ensinamento russo. Já que os udi são os legítimos herdeiros do cristianismo da Albânia Caucasiana, a primeira tradução para o udi moderno ocorreu de forma completamente canônica a partir da tradução de um exemplar russo do Evangelho. Entre 1931-1933, a instrução dos udis era feita na língua materna e, desde 1937, no Azerbaijão ela foi feita em língua azeri, depois em russo, e na Geórgia em língua georgiana. Hoje a língua udi conta com cinquenta e dois sons e utiliza um alfabeto elaborado sobre uma base latina com sinais suplementares e ensinado, na língua materna, nas classes primárias das escolas secundárias de Nij. Em 2010 foi publicado um dicionário udi-azéri-russo compreendendo mais de 9000 vocábulos, grupos de vocábulos, expressões estáticas e idiomáticas. $\mathrm{O}$ autor dedicou esta obra ao eminente estudioso e linguista $\mathrm{Vo}$ roshil Gukasyan. (fig. 6) 


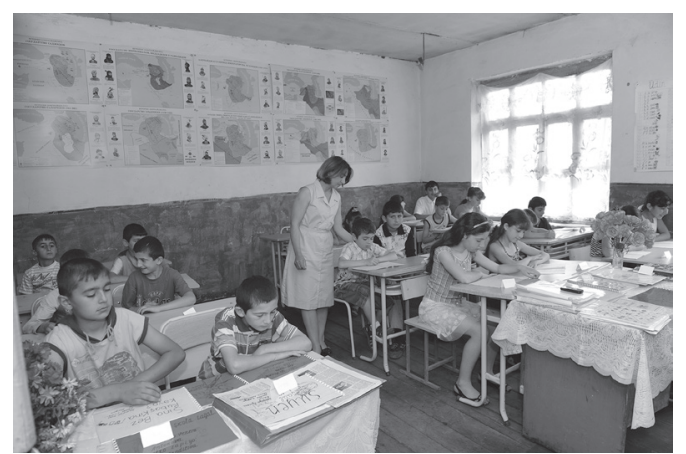

Fig. 6. Lição de língua udi na escola primária de Nij. Azerbaijão, 2013. Foto do autor.

\section{A religião}

A Igreja Udi-albanesa na condição singular de herdeira legítima da Igreja Albanesa é uma das mais antigas igrejas, não somente do Cáucaso, mas também do mundo cristão. Segundo antiquíssima tradição as sementes do cristianismo foram lançadas pela primeira vez sobre a antiga terra azerbaijana no século I, por um dos doze apóstolos de Jesus Cristo, São Bartolomeu Apóstolo que foi martirizado na cidade de Albanopol (a moderna Baku) ao pé da Torre da Virgem. Sua obra de evangelização foi continuada por Santo Eliseu, o primeiro bispo albanês e discípulo de São Judas Tadeu Apóstolo e é por isso que São Bartolomeu Apóstolo é a maior figura espiritual da Albânia Caucasiana. A difusão do cristianismo no território da Albânia Caucasiana conhece dois períodos, o primeiro denominado "sirófilo" e o segundo "helenófilo" e está ligada à tradição dos acontecimentos que se produziram no meio do século I d.C. quando Santo Eliseu construiu a primeira igreja em Gis (a moderna Kish). Segundo a referida obra de Moisés Kalankatuatsi, parece evidente que a Igreja albanesa era inicialmente apostólica, oriunda da "missão palestinense", através do "apóstolo" Santo Eliseu que de Jerusalém foi à Pérsia e de lá à Albânia. Em seguida, Eliseu chegou ao território udi indo para Kish, onde construiu uma igreja e, para oferecer sacrifícios, aceitou a ideia de uma vítima ritual que não fosse impura e da qual não se faria derramar sangue. Depois o apóstolo Eliseu partiu de Kish para Gelmets onde a primeira pregação da Boa
Nova do Evangelho não foi coroada de sucesso, pois os pagãos o martirizaram e jogaram seu corpo em um fosso. Muitos anos após esses acontecimentos o rei Vatchagan III, o Piedoso, ordenou a construção de uma capela sobre o fosso perto de Gelmets onde o corpo do apóstolo havia sido jogado. Seus restos mortais foram então transferidos e inumados. Por ordem do rei albanês Urnayr, em 313, o cristianismo na Albânia Caucasiana tornou-se uma religião de Estado. Possuímos abundantes informações sobre o período helenófilo da difusão do cristianismo na Albânia Caucasiana. Neste período, o cristianismo tornou-se religião de Estado e a Igreja Albanesa se entrega a uma grande atividade missionária. Constroem-se igrejas, capelas e mosteiros. Várias dessas construções, apesar da dominação posterior do Islã, foram conservadas até os dias e hoje. Particularmente numerosas em Karabakh e na zona de Gabala, Shaki e Zagatala. Em 1912, por iniciativa da Academia de Ciências Russa, fizeram-se tentativas para restaurar estes edifícios e, em particular o monastério e a igreja de Lekit, localizados no povoado de Kum. Durante o período "helenófilo", a Igreja Albanesa, menos dependente de Bizâncio do que as igrejas georgiana e armênia, continuou a cooperar com a Igreja de Jerusalém. (fig.7)

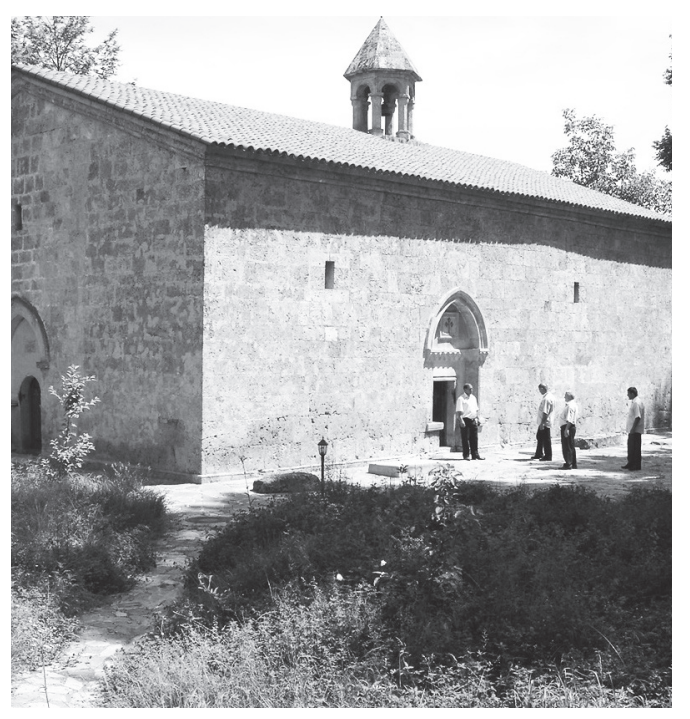

Fig. 7. Igreja de Santo Eliseu (Chotari). Nij, região de Gabala - 1723-1726. Azerbaijão, 2014. Foto do autor. 
O reforço dessa Igreja Albanesa foi favorecido por sua estrutura. De um ponto de vista hierárquico, a Igreja Albanesa se submetia à igreja Romana, entretanto, no início do século IV ela recebia apoio dos hierarcas de Jerusalém, mas supõe-se que por volta de 340 a Igreja Albanesa tornou-se autocéfala. A igreja local já tinha seu metropolita cuja residência se encontrava em Partav (Barda) e contava com oito dioceses. Em 551, a Igreja albanesa rompeu seus laços com Bizâncio e seu líder espiritual começou a ser chamado de catholicós. No século IV, o centro religioso ficava na cidade de Gabala, mas a partir do século $\mathrm{V}$, deslocou-se para Barda onde o líder da Igreja Albanesa fazia a imposição das mãos na ordenação de seus padres. Posteriormente Sunik passou a ser o lugar consagrado para a imposição das mãos pelo catholicós. Nesta época o processo de expansão do cristianismo foi suspenso e depois completamente paralisado com o aparecimento do Islã. Após o destronamento do rei Bakur (688-704), a Igreja Albanesa perdeu a autocefalia e o Califa Abu-al-Malik (685-705) submeteu parcialmente a Igreja albanesa à Igreja armênia. Nesta época "o catholicós da Albânia, cujo trono se situava em Partav, havia selado um acordo com o Imperador romano mencionando-o em suas orações e forçando o país a se aliar a ele adotando a doutrina calcedoniana e aceitando sua proteção”. A submissão ao catholicós armênio marcou o início do enfraquecimento da Igreja Albanesa e formalmente o catholicós albanês (cuja residência nos últimos séculos se encontrava em Gandzasar) existiu até 1836, depois foi suprimido pelo Czar Nicolau I por decisão do Santo Sínodo da Igreja Ortodoxa Russa, o que colocou fim a existência, mesmo nominal, à Igreja Albanesa e as paróquias que dependiam dela foram indiretamente subordinadas ao catholicós de Etchmiadzin. A Igreja Armênia apoderou-se das igrejas albanesas, de sua chancelaria, assim como de sua Representação em Jerusalém, que era transmitida à Igreja Albanesa porque apostólica e autocéfala. Hoje a Igreja Albanesa restaurada na República do Azerbaijão tem a possibilidade de pedir a restituição de sua representação em Jerusalém e tem a qualidade de membro do Conselho Mundial de Igrejas.
Em 1997, por acaso, após um incêndio no Mosteiro de Santa Catarina no Sinai, Egito, descobriu-se um palimpsesto georgiano e albanês (fig. 8). Sobre as folhas guardadas intactas desse palimpsesto albanês, um membro correspondente da Academia de Ciências da Geórgia, Zaza Aleksidze, decifrou graças à

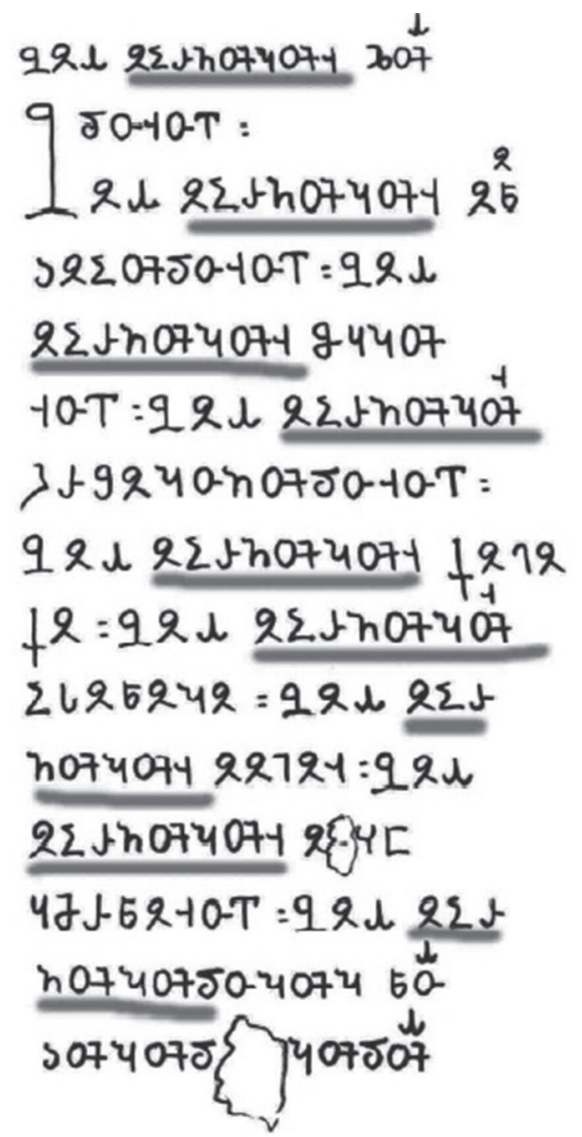

Fig. 8. Palimpsesto com a antiga escrita albanesacaucasiana. Zaza Aleksidze percebeu que uma certa passagem no palimpsesto albanês repetiu a mesma palavra nove vezes em rápida sucessão. Isto levou a sua decifração. Ele sabia que a passagem bíblica havia sido a partir de cartas do Apóstolo Paulo aos cristãos de Corinto. Esta passagem é de 2Cor 11, 26-27. A palavra repetida é marakesunukh que significa "eu fui perseguido”. In: Aleksidze, Z; Blair, B. The Albanian Script. The Process - How Its Secrets Were Revealed. http://azer.com/aiweb/categories/magazine/ai113 folder/113_articles/113_zaza_aleksidze_secrets.html 
língua udi moderna, passagens do Evangelho (capítulos dos evangelhos segundo Mateus, Lucas e João), epístolas sinódicas de Pedro, Tiago e João, e as epístolas de Paulo aos Tessalonicenses, Timóteo, Tito e aos Hebreus. A tradução deste texto só foi possível graças à língua udi. Este lecionário albanês é muito próximo ao lecionário georgiano "Khanmeti". A descoberta de um lecionário albanês é por si só uma prova da existência de traduções dos evangelhos e das epístolas em língua udi e deduz a existência no passado de uma versão da Bíblia em albanês caucasiano, pois somente um povo que possui o texto completo da Bíblia escrito em sua própria língua pode possuir um lecionário. A passagem definitiva à ortodoxia dos grupos ocidentais dos udis começou entre os séculos XI ao XIII. Desde o século XVII os catholicoi da Igreja Albanesa se instalaram no templo de Khatchen. Um dos objetivos da política oficial da Rússia após a anexação da Transcaucásia ao seu território foi a restauração da Ortodoxia (ressaltam-se os missionários ortodoxos I. Bezhanov, S. Bezhanov entre outros). Em 1893, Simon Bezhanov traduziu todo o Evangelho para a língua udi. Nos arredores de Oghuz (Vartashen), o udi ortodoxo Zinovij Silikov construiu o Mosteiro de Santo Eliseu, mas após o decreto do Czar Nicolau I, este mosteiro passou à jurisdição da Igreja Armênia. Com relação aos fatos evocados acima, por iniciativa de intelectuais udis, em 10 de abril de 2003, a comunidade cristã udi-albanesa foi registrada no Comitê Estatal para as Comunidades Religiosas do Azerbaijão. Tal registro é um primeiro passo em direção ao renascimento da Igreja Apostólica Albanesa Autocéfala. Hoje, com a ajuda da Organização Humanitária Norueguesa do Reino da Noruega, a Igreja de Santo Eliseu de Kish (considerada como mãe das igrejas do Cáucaso) foi restaurada. Em 19 de maio de 2006, realizou-se a cerimônia de inauguração e de consagração da Igreja "Tchotari” da cidade de Nij. Também foram iniciados os trabalhos de restauração de uma das igrejas ortodoxas no território do distrito de Oghuz e em breve será concluída a restauração da Igreja "Geyün” de $\mathrm{Nij}$ e em todas estas igrejas os ofícios religiosos serão assegurados na língua vernácula pelos membros da comunidade udi. (fig. 9)

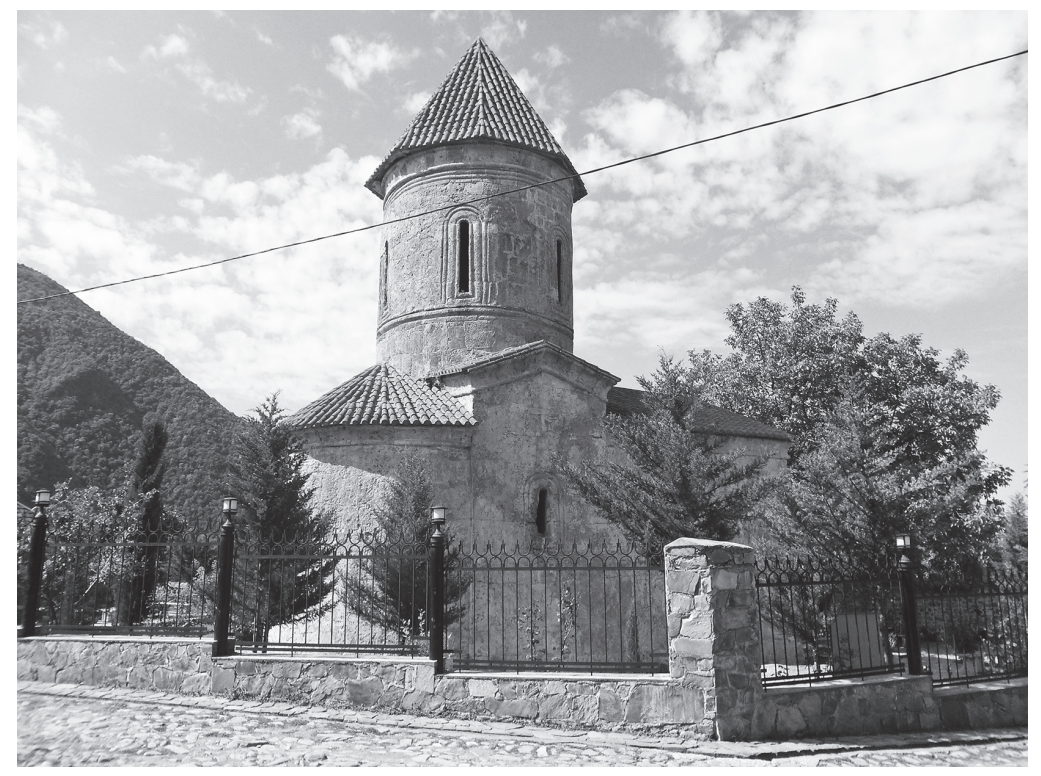

Fig. 9. Igreja de Santo Eliseu na vila de Kish, região de Shaki. Igreja mãe das igrejas orientais (final do século I, início do século II). Kish. Azerbaijão, 2014. Foto do autor. 


\section{A etnografia}

\section{Agricultura}

Os udis eram sedentários, praticavam a agricultura, horticultura e mercado de jardinagem, artesanato e pecuária diversificada. Agricultura e horticultura desempenham um papel essencial na economia de Udis ligados a um estilo de vida sedentário e fertilidade. No século XIX os udis eram famosos pelo cultivo de trigo, arroz, seda, jardinagem e hortas. Semeavam trigo, cevada, arroz, milheto e milho. Todos os tipos de cereais cultivados nesta região eram conhecidos dos udis tanto que, até 1960 , preferissem entre todas a cultura do arroz. No fim do século XIX somente no povoado de $\mathrm{Nij}$, que então somava cinco mil seiscentos e oitenta pessoas (recenseamento de 1897), funcionavam trinta moinhos movidos a água e mais de cem debulhadoras de arroz (ding). Até mais recente, outra produção agrícola básica para a economia udi era a cultura do tabaco, como testemunha a atribuição soviética, entre 1953 e 1955, do titulo de "herói do trabalho socialista" a três habitantes de Nij - T. Tchaldallakova, T. Mobili e S. Dallari - por terem plantado as melhores qualidades de três tipos de tabaco: o trabzun, samsun e o virginia.

\section{A fruticultura}

Ao lado da cultura de cereais e da criação bovina, a fruticultura ocupa um lugar peculiar. Desenvolveu-se por toda parte onde dominam os pomares e as plantações de nogueiras e de aveleiras. Os pomares estão espalhados sobre todo o território, do mesmo modo que as plantações de nogueiras, castanheiras, amoreiras e a videira. A noz, a castanha e a uva eram consumidas no local e somente uma pequena quantidade era exportada ou trocada por pão. $O$ principal produto de exportação era a avelã além dela cultivam-se várias espécies de maçãs tais como a sinap, gyzyl-ahmedi (ahmed vermelha), arainette, e de peras, como a duquesa, a kotoshi, a bazumburi, assim como o cornisolo, vários tipos de ameixa, damasco, marmelo, nêspera, caqui e o figo.

\section{A cultura das hortaliças}

Na região se planta pepino, tomate, cebola, alho, pimentões de diversos tipos, berinjela, beterraba, cenouras, melões, melancia, abóbora e suas diferentes variedades (kotosh, pashna), funcho, menta e outras variedades de ervas finas. É preciso assinalar uma espécie particular de pepino: o pepino branco produzido na região de Matsikatchuli, que é o legume de base utilizado para conservas. Para a cultura de hortaliças, eram utilizados utensílios como penets, o beli, a gaba, o mikh e o gor-gor.

\section{A criação de animais}

No território densamente povoado pelos udi, situado nos contrafortes das montanhas e nos vales, a criação de animais domésticos foi sempre muito desenvolvida. Sendo prioritária a agricultura, os udis, consideravam a criação de animais como um ramo secundário e auxiliar da economia. Entretanto, na pecuária a criação bovina e suína ocupam o primeiro lugar. Sendo que esta última desempenha na economia dos udis uma atividade comercial de primeira ordem (fig. 10). Na primavera deslocavam-se a vara de porcos, as tropas de gado e cavalos para as pastagens situadas no sopé das montanhas e no outono eram reconduzidos aos estábulos. Da pecuária os udis retiram para a alimentação as carnes bovina e suína, laticínios como a manteiga, queijo de ovelha (labrynza), l'ayran

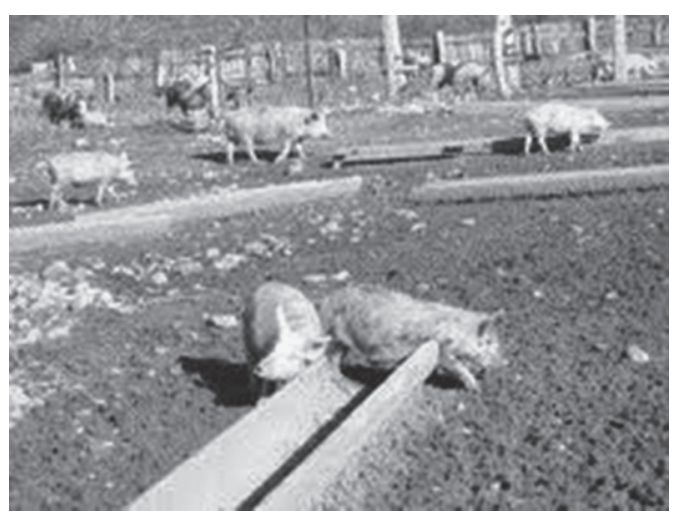

Fig. 10. Fazenda com criatório de porcos. Região de Nij. Azerbaijão, 2012. Foto do autor 
(lebas-beurre), nak, shor (tipo de queijo branco escorrido chamado tvorog na Rússia), o tchiayi e otchio.

A cozinha udi é muito variada e tem muitos pontos em comum com a cozinha dos azerbaijanos e com outros povos do Cáucaso, cujos pratos contêm farinha, produtos derivados do leite, carne e legumes.

Os pratos tradicionais dos udis são o dólmã (goloubtsy em russo), os dolma recheados de nozes, a sopa de feijões, o lykyrti otchorotori, o tchilov tipo de plov sem manteiga com vagens), o doghadj (sopa branca com ervas finas chamada também dovgha em azerbaijano, o khashil, o yakhni, o siyokh (tipo de arroz ao leite com carne), o matsi siyokh (arroz ao leite sem carne com ervas), o shyltiri (sopa de castanhas), o shyftili (molho a base de castanhas e de noz), o iyankkh (molho a base de feijão e de noz), o khup, o döshamalikhup (plov com frango) e ainda muitos outros.

É necessário mencionar a kharisa, trigo cozido até tornar-se uma forma pastosa à qual se acrescenta uma grande quantidade de manteiga e pedaços de carne ou de ave. A kharisa é o alimento tradicional dos agricultores. Este prato era conhecido na Ásia Menor e na Síria, o qual foi copiado pelos udis e países vizinhos assim como seu nome.

Produtos vegetais como feijões, arroz, nozes, castanhas, legumes, uma grande variedade de finas ervas, frutos e bagas representam um papel importante na alimentação dos udis. As carnes mais consumidas são: vitelo de porco, carneiro mas também carne de aves e particularmente de peru. (fig. 11).

O prato principal dos udis são o porco e o peru. Nas festas tradicionais, os udis, por respeito aos hóspedes azerbaijanos muçulmanos, não utilizam nem comem carne de porco, cozinha-se pão feito à base de farinha de trigo em um forno denominado tarrné. Os diversos tipos de plov são opções a mais na alimentação: constituído de uma base de arroz, acompanhado de vagens, pimentão, uva-passa, caqui, castanhas e de noz. O arroz se comia também com leite coalhado azedo. Apreciam-se as castanhas cozidas na panela com água, que os udis vendiam aos comerciantes de Baku e de Tiflis.
A partir das nozes, fabrica-se o óleo de noz. Na cozinha dos udis encontramos muitos pratos a base de legumes e particularmente abóbora ou abóbora menina, couve, berinjela, tomate.

Utilizam-se ervas selvagens, particularmente urtigas das quais se fazem sopas, recheio de aves para lesafars (tipos de crepes finas com ervas) e os khingal (tipo de raviólis com carne, temperados com alho e ervas), frutas, bagas e laticínios são alimentos importantes para os udis que fazem fermentar o leite, produzindo diferentes tipos de cremes frescos como o tchio etc., a manteiga fresca e a manteiga.

Durante as refeições festivas e as recepções de hóspedes de honra eram obrigatórios pratos de carne como o peru fatiado e cozido, ao forno e no espeto (o fyrrama), 'tchyghyrtma, frango (tcholpa), os dolma recheados com carne e com nozes. Os pratos de carnes de vaca, carneiro, porco, peixe de água doce, diferentes tipos de omeletes, o kükü.

As bebidas são: cozimento de bagas, frutos secos, erva e de polpas das nozes verdes, cachaça de abrunho, de cornisolo, de ameixa, da amora madura, e do mosto da uva (tchetcha). Não se deve esquecer da grande seleção de vinhos elaborados a partir de espécies de uva locais como a shalab, figombal, merendi, matsitul, maintul ou importados como o mousquet e o moldovanka.

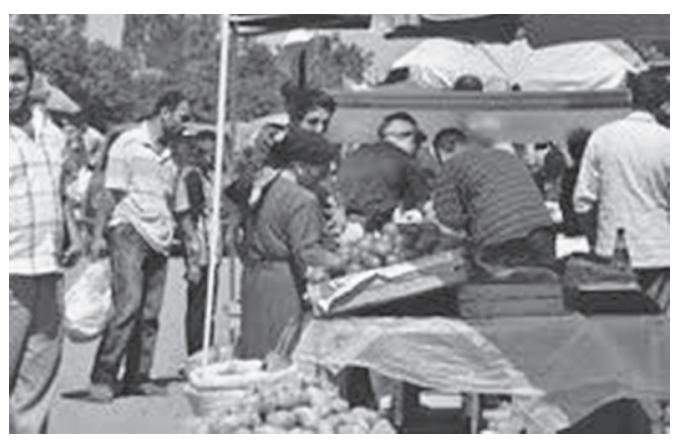

Fig. 11. Feira dominical de produtos alimentícios em Yakmarka, proximidades de Nij. Azerbaijão, 2010. Foto de Argo Mobili. 


\section{$\mathrm{O}$ vestuário}

O vestuário tradicional dos udis é similar aos vestuários dos azerbaijanos e de outros povos do Cáucaso. Os homens usam a tchokha túnica longa e chanfrada no peito com um largo colarinho, por baixo, mais curto o arkhaluk, hermeticamente fechado, a camisa justa com um colarinho montante (o gurat); e enfim como calças, o kyolyokh. O arkhaluk se amarrava com um cinto ornado de placas de prata e no qual era colocado um punhal, o kindjall. Nos pés, usavam meias de lã tricotadas nos sapatos de couro não curtido (os tcharykh) ou em sapatos feitos com um couro mais macio os tchust e os torokal.

$\mathrm{O}$ vestuário feminino era composto de largos e longos calções por cima dos quais as mulheres vestiam uma saia muito larga. Por cima usavam um longo arkhaluk que ia até os joelhos, franzido na cintura e com aberturas em toda a extensão das mangas. $\mathrm{O}$ arkhaluk era ajustado ao corpo por um largo cinto de prata fechado com uma considerável fivela para os mais ricos e, para os mais modestos, um cinto de pano, o kuchtuk. Nos pés meias tricotadas e os tcharykh. O chapéu feminino chamado dagka, era um conjunto complexo e peculiar com vários elementos. Primeiramente, ajustavase na cabeça um tipo de tioubitieyka redondo (o katar) sobre o qual se amarrava o tchelebend, constituído de dois triângulos de pano, unidos entre si, por um laço, cujas extremidades eram atadas sob o queixo. Este conjunto formava a dagka sobre a qual colocava-se em seguida um pequeno lenço triangular branco, o yaligat, e enfim um outro pequeno lenço o tepelik cujos cantos eram também atados sob o queixo. $\mathrm{O}$ conjunto era recoberto com um grande xale preto. As mulheres udis casadas encobriam a parte inferior do seu rosto com um lenço chamado yashmag.

Em meados do século XX, os vestuários tradicionais dos udis desaparecem, despojados pelos vestuários contemporâneos comuns. $\mathrm{O}$ udis de hoje usam vestuários semelhantes em todos os pontos àqueles comuns usados de maneira habitual, segundo as exigências da moda, da estação ou da temperatura. (fig. 12)

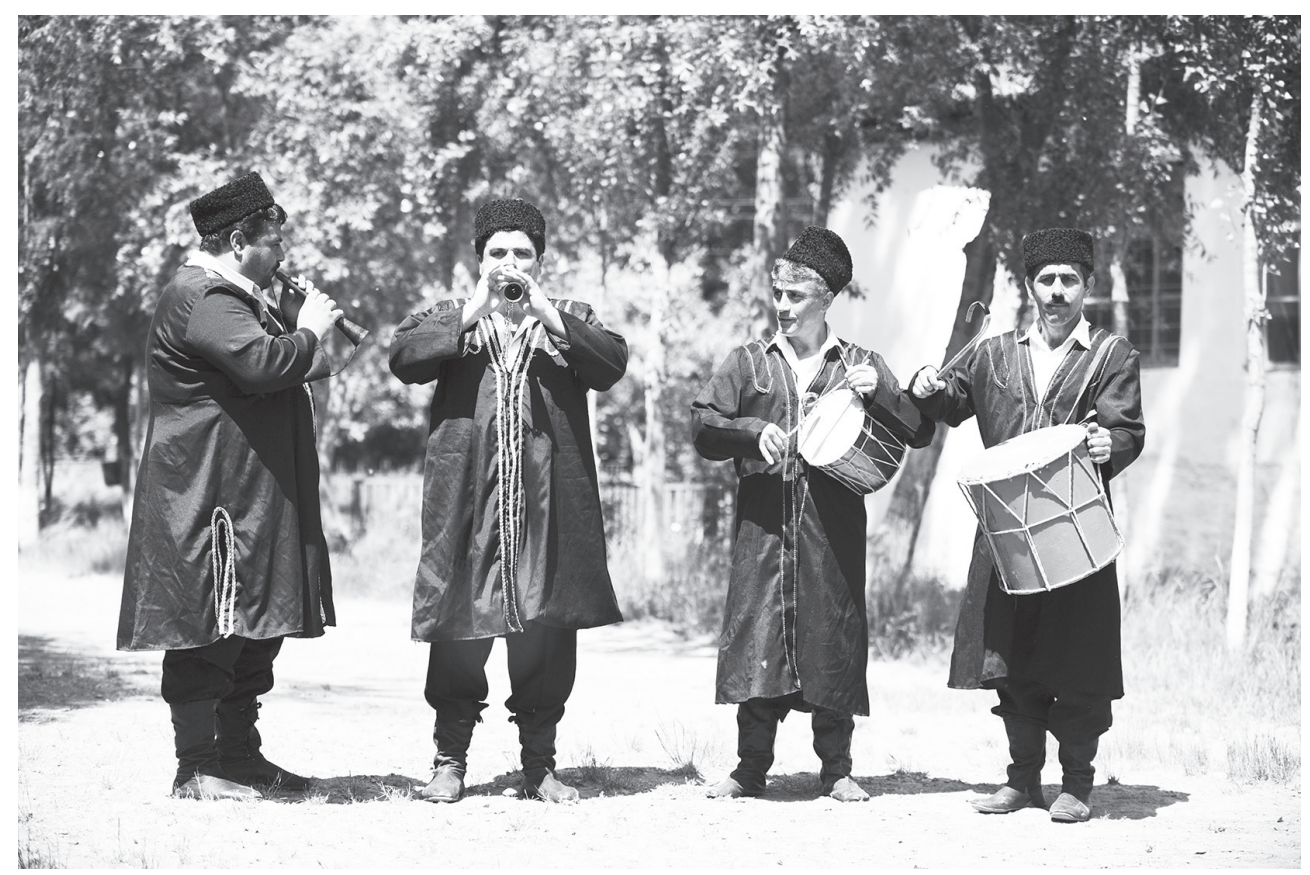

Fig. 12. Grupo musical udi. Nij, 2013. Foto do autor. 


\section{Folclore e tradições}

O folclore dos udis é extremamente variado: canções líricas ou guerreiras, danças, contos sobrenaturais, lendas, provérbios e adágios estão estreitamente ligados ao modo de vida e a atividade econômica comum ao mundo do trabalho. Uma parte se conservou até os dias de hoje, outras formas de expressão são conhecidas através de documentos manuscritos do século passado. Na base da antiga língua udi, foram elaborados um alfabeto e uma escrita que permitiram a tradução de obras procedentes de outras línguas, mas também a emergência de uma literatura original. Apareceram escritores e historiadores, poetas e retóricos, juristas e filósofos, algumas de suas obras chegaram até nós tais como os "Cânones Augen" do séculoV, as "Lamentações Sobre a Morte do Príncipe Djavanshir de Gardman”, do poeta Davdak (século VII), a "História dos Albaneses", de Moisés Outiyski, a "Crônica Albanesa" e o "Código das Leis", de Mhitara Gosha (século XII), a "História”, de Kirakos Gandzakski e "Os Cânones", de David Gandzaski, que viveram no século XIII, assim como os monumentos epigráficos do Azerbaijão e do sul do Daguestão.

Após a conversão do clã udi ao cristianismo, como de outras tribos albanesas, os udis não esqueceram seus costumes, seus ritos, suas tradições e os integraram a sua nova religião. Por exemplo, conservaram os hábitos tradicionais de manter no lar um fogo perpétuo que testemunha a veracidade da sobrevivência dos zoroastrismo. Os udis adoravam a lua que era para os albaneses a divindade principal. Ainda hoje os udis, mesmo sendo cristãos, elevam frequentemente orações à lua. Não é por acaso que os udis albaneses relacionavam o nome deste astro khash ao símbolo e ao nome da cruz. Para designar o ato de se batizar, a língua udi guardou os termos de khashdessun e pul khash. Entre outros objetos de adoração, havia o sol, o fogo, as pedras sagradas, as árvores, os riachos e as fontes. Diversas crenças, práticas adivinhatórias e mágicas eram propagadas. Os curandeiros que tratavam das doenças e expulsavam o mau olhado, gozavam de uma grande influência e o culto aos antepassados era muito pratica- do. Pode-se citar igualmente o costume que consiste em venerar os odjag que são lugares considerados sagrados situados fora da aldeia, que foram assimilados ao culto cristão como o odjag, o pequeno bosque sagrado, ao redor da Igreja Santo Eliseu ou os "odjags" de São Jorge, Kömrat, Tchotari, Yalovlityapi e Bulun. A ligação deles com o fogo, além da etimologia do termo, aparece moldada num amontoado de pedras, encimado com uma vela. Realmente, o papel sagrado do odjag é superior ao da igreja. Conservando seu particularismo, os Cristãos udis sofreram a influência do ambiente mulçumano, do qual encontramos traços na língua, hábitos, práticas culturais e tradições.

Os udis adotaram o calendário Juliano (também chamado em russo de o antigo estilo) como calendário eclesiástico e litúrgico cujas festas mais importantes são:

Natal - Miladi Ahsibay. Os udis de confissão ortodoxa celebram o dia 25 de dezembro segundo o calendário "antigo estilo", que corresponde ao dia 7 de janeiro no calendário "novo estilo" (gregoriano) e o dia 6 de janeiro segundo o calendário gregoriano monofisista (usado pela igreja Apostólica Armênia).

Ano Novo - Taza Usen. A festa do Ano Novo no calendário é celebrada de maneira tradicional e solene pelos udis. $\mathrm{O}$ atributo obrigatório para esta festa é o peru fatiado (fyrrama) cozido no espeto em forno de madeira.

"Meia Quaresma" - Esta solenidade é comemorada na quinta-feira da $3^{a}$ semana da quaresma. Nesta data não temos informação sobre esta festa.

Quaresma-Ghurukh ou Kala Ghurukh (pronunciado ghurukh ou girukh.), significando etimologicamente "os dias". Trata-se de um grande jejum que dura sete semanas e que termina na Páscoa.

Domingo de Ramos - Zarazartar. Neste dia todos os jovens e senhoras vão à igreja. É o único dia do ano em que os jovens de ambos os sexos se reúnem na Igreja.

Páscoa - Beyin (a Ressurreição) ou Kala Ahsibay (literalmente: "a grande festa", a "Ressurreição”) (figs. 13a, 13b).

Primeiro Dia [da Páscoa] - É uma grande festa religiosa. O Sacrifício (oferenda a Deus) é 
realizado próximo ao recinto da igreja. A decoração dos ovos. Os habitantes de $\mathrm{Nij}$ celebram frequentemente esta festa reunindo-se nas áreas das igrejas Tchotari, Bulun e Geyün no último domingo de abril segundo o calendário solar.

Segundo Dia - A visita aos mortos no cemitério Mayin Ahsibay (literalmente "festa negra"); plov, castanhas cozidas, frutas, massas de bolo e doces são servidos com bebidas (diferentes tipos de vinho e ponche).

Terceiro Dia - A Festa Paroquial. Acontece em Kala Gergets (literalmente "Grande Igreja") e no Mosteiro de Santo Eliseu.

Festa de Maio - Maye Ahsibay (literalmente: "festa de maio"). Atualmente esta festa é celebrada solenemente pelos udis nos dias $1 \mathrm{e}$ 2 de maio.

Ascensão - Gokma (palavra cuja etimologia significa "brincadeira", "torre de magia", "milagres”). É festejada numa quinta-feira, quarenta dias após a Páscoa.

\section{Festa do Renascimento da Primavera} - Esta festa é celebrada no dia 19 de maio, a
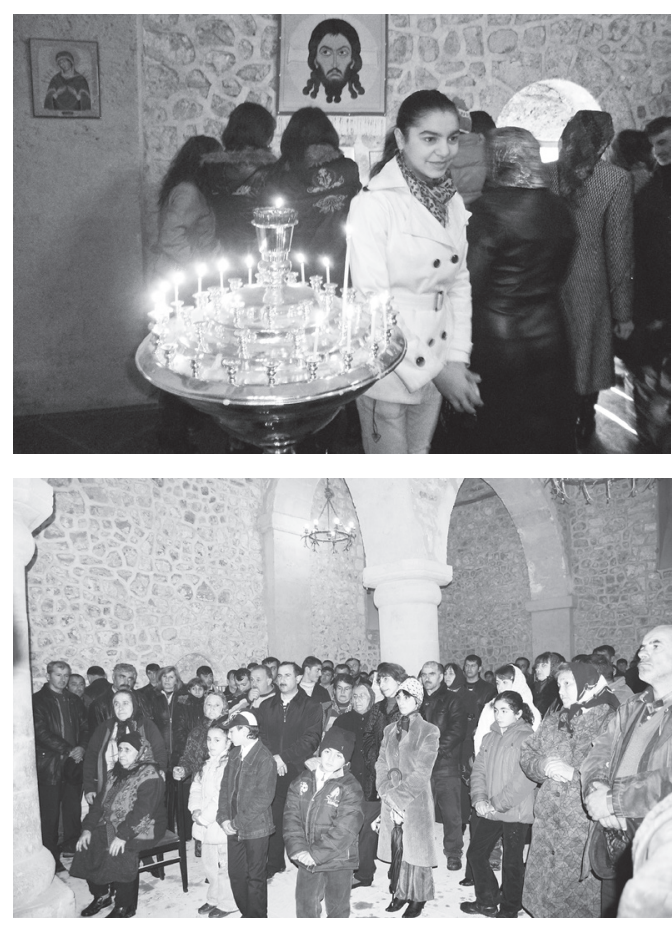

Figs. 13 a-b. Páscoa na Igreja de Santo Eliseu - Nij. Azerbaijão. 2013. Foto do autor. partir da data da cerimônia da restauração da igreja udi Tchotari no dia 19 de maio de 2006 e do registro oficial da comunidade cristã udi-albanesa em 19 de maio de 2003 (fig. 14).

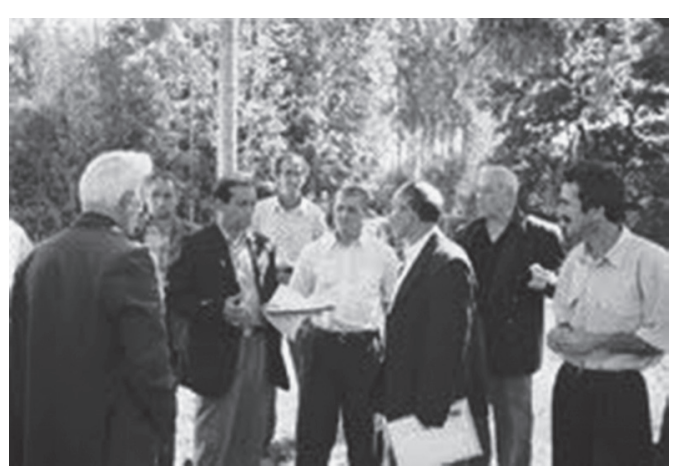

Fig. 14. Ativistas udi-albaneses da comunidade cristã durante uma discussão em abril de 2008. Nij, Azerbaijão

Transfiguração - Vartiver. Na véspera desta festa, as jovens coloriam as mãos com bálsamo (os noivos a ofereciam às suas noivas com essa finalidade) e iam se reunir nas proximidades da igreja e perto do odgag de São Jorge.

A Festa da Colheita - Bare Ahsibay (literalmente "festa da colheita"). A data da celebração desta festa corresponde ao último domingo de outubro.

De fato, os modos de vida sedentários e a preeminência de uma atividade ligada ao trabalho da terra fazem com que a maioria dos ritos, cerimônias, das festas e das grandes datas do calendário, estejam ligados à agricultura. Por exemplo, a consagração da vinha. No léxico dos udis foram conservados até os dias de hoje nomes de alguns meses ligados à atividade agrária pertencentes a um passado longínquo: tule/tuen, o"mês da uva", namots/kamots, o "mês úmido", tsile/shili, o "mês das sementes", bokospin, o "mês cor de fogo", tsile/shili, o "mês das sementes", yekhniya/yekhina, o "mês das colheitas", khabniya/khibna, o "terceiro mês".

Os udis possuem uma longevidade excepcional: atingem a idade de oitenta, de cem anos e mais. São hospitaleiros, prontos a se ajudarem em todas as ocasiões e respeitosos em relação 
aos mais velhos. Os udis se casam cedo: os rapazes aos dezesseis anos e as moças aos treze ou quatorze anos. Preferem escolher seus parceiros no seio de sua comunidade, mas obedecem a interdição mais severa dos casamentos consanguíneos, aí incluída com os parentes mais afastados ou somente associados à família por aliança e em todo caso nunca antes de um distanciamento de sete gerações. Num passado muito longínquo, a família udi era numerosa, do tipo patriarcal, cujos membros, muito unidos por seus laços de sangue viviam de uma maneira compacta reagrupados em "bairros familiares". Em cada bairro havia um chefe, como de hábito o mais velho de uma família numerosa, dirigindo os trabalhos dos campos e do jardim. O pai é o chefe soberano da casa a quem obedeciam sem queixas todos os membros da família.

Os udis, no passado, levavam um modo de vida bastante concentrados neles mesmos: as mulheres cobriam seus rostos, comiam separadamente dos homens, não ousavam intervir em uma conversa com os estrangeiros sem a permissão do marido; não tinham o direito de sair de casa sem a autorização dos mesmos. As cerimônias do casamento udi começavam pela manhã e se prolongavam em um círculo restrito de parentes durante três dias. Jogava-se tar, kamantcha, def, zurna e balaban. Atualmente nos casamentos udis, cantam-se canções azerbaijanas. Os convidados se divertem cantando e dançando. Entre as danças praticadas ressaltamse o uzundere e o vakzali. Entre os udis como entre os autóctones do Azerbaijão, é dançado o yally desde tempos imemoriais. A criatividade que se ilustra em numerosos domínios e gêneros do patrimônio oral udi, atesta as raízes antiquíssimas da cultura e da espiritualidade desse povo. Entre todos os gêneros da cultura popular, convém citar os relatos míticos da criação, os gestos épicos e heroicos, as parábolas religiosas, as crônicas históricas, as cerimônias culturais ligadas aos elementos naturais (a água, o fogo, o raio, o granizo, a terra). Nas diferentes lendas, as crenças populares e as mitologias udis à lua, o sol e o fogo ocupam um grande espaço. Os ritos udis encontram seu fundamento nos cultos antigos da fartura, da prosperidade e da fecundidade.

\section{Provérbios udis}

- Por menor que seja o tamanho de sua terra, ela é a sua pátria.

- No verão trabalha, no inverno descansa.

- É na panela que a noz é cozida.

- Sem amigos você se transforma em um morto vivo.

- Aquele que peca pela língua paga com sua cabeça.

\section{Algumas anedotas udis}

- Um avô levou seu neto ao mercado. À noite, a avó perguntou ao seu neto: "Meu pequeno, o que você viu no mercado?". Ele lhe respondeu: "O que eu vi? Vi como se tosquiam os carneiros e como os dependuravam aos ganchos de ferro". ${ }^{1}$

- Em certa aldeia, um udi havia recebido o apelido de "rabo". Quando a gente lhe perguntava por que lhe haviam dado tal apelido, tão ridículo, ele respondia: "Em nossa aldeia, muitas pessoas recebem apelidos designando nomes de animais e das partes de seus corpos. Quando chegou a minha vez, sobrara somente o rabo e é por isso que recebi tal apelido".

- Um udi ouviu dizer que aquele que cai de um corniso (árvore comum dos bosques do Azerbaijão) se transformava em jumento. Um belo dia, em um pomar, ele caiu de um corniso. Após ter retirado a poeira de seu corpo, pediu a sua mulher: Mulher cuide para que ninguém saiba que caí de um corniso, pois tenho medo de me transformar em um jumento".

1 Significado da anedota: no leste, ou seja, na Ásia Caucasiana, Bazaar é um lugar não só de comércio, mas também de demonstração da sociedade local. Em uma palavra: Bazaar é um barômetro da vida e grupos étnicos na região. Então, o avô levou o neto para mostrar a sua comunidade, sua cultura, costumes e tradições. Mas já que era pequeno, não consegue perceber o significado do bazaar, mercado, vendo apenas como os ovinos eram tosquiados e abatidos para a carne e seu couro pendurado em um gancho (gancho de ferro). Portanto, o significado desta anedota é que o avô queria mostrar tudo de melhor na comunidade, mas o netinho só viu o couro das ovelhas. Tudo o mais não pôde avaliar porque era criança. Assim esta anedota quer demonstrar que muitas vezes uma pessoa é imatura para compreender uma realidade. 
E a mulher lhe respondeu "Vai trabalhar, não tema, os jumentos não podem se transformar em jumentos".

\section{Personagens}

Os udis, como outros povos azerbaijanos, participam ativamente da vida social e cultural da República do Azerbaijão. Desde 1957 vários e relevantes representantes da comunidade udi realizaram todos seus estudos em idioma azerbaijano ou em russo e trouxeram contribuições à ciência e a cultura de seu país. Eis alguns dados biográficos de udis famosos:

- Voroshil Levonovich Gukasyan (19321986): célebre sábio udi, oriundo da aldeia de $\mathrm{Nij}$, linguista e orientalista, doutor em filologia, escreveu notáveis e preciosos artigos científicos e também notáveis monografias sobre o antigo turco e as línguas udie e azerbaijana. É o autor do primeiro dicionário udi-azéri-russo.

- J. Aydynov e George Kechaari: são os autores dos manuais das classes primárias das escolas udis. Convém sublinhar aqui o trabalho colossal realizado por George Kechaari, autor de uma compilação de contos, de narrações de lendas e de anedotas udis. Do mesmo modo, é preciso cumprimentar Minani Mayisa Kochari pelos seus versos e narrativas de recordações.

- Richard Arami Danakari: doutor em ciência filosófica, professor e chefe da cadeira de filosofia da Universidade do Estado de
Volgograd, se consagra há numerosos anos ao estudo científico dos problemas étnicos encarados como problemas de filosofia social.

Entre os representantes das classes intelectuais udi é necessário assinalar a plêiade de eruditos procedentes da família Bezhanov, que forneceu uma contribuição considerável ao conhecimento da etnografia udi.

É preciso também louvar a parte da contribuição de Yuri Dallara ao progresso técnico do país. Memoráveis também são os padres Zino Silikov e Pak que defenderam tenazmente a Igreja e a cultura udi-albanesa. Enfim, os udis se orgulham de seus compatriotas, os irmãos Stepan e Semyon Patchikov, que fazem parte da corporação "Microsoft". (fig. 15)

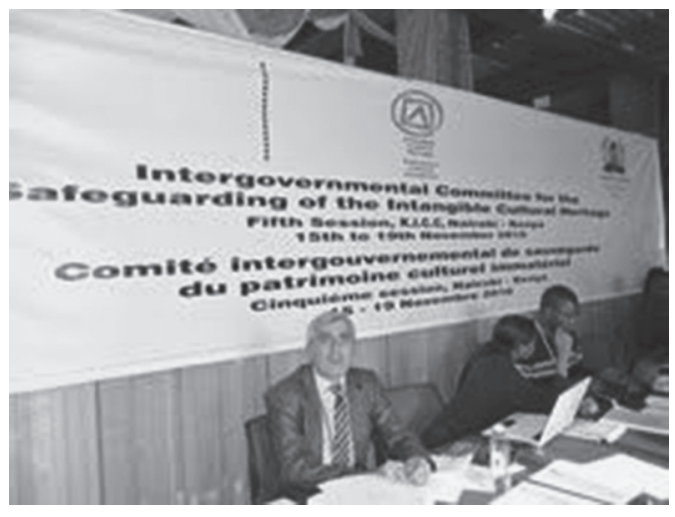

Fig. 15. Sr. Robert Mobili, presidente da Comunidade Udi em sessão da UNESCO. Nairobi. Quênia, 2010. 
BAQRATOVIC MOBILI, R. The Udis: a language, a religion, and ethnography. R. Museu Arq. Etn., 24: 163-179, 2014.

Abstract: This article presents the history and ethnography of the udi-Albanian people ethnic minority in Azerbaijan and one of the oldest cultures of mankind with continuous history. Remnants of the ancient Kingdom of Albania in the Caucasus, they retained the native language, customs and Christianity amid the ancient Islamic rule. Currently they have representation in the government of the Republic of Azerbaijan and are in the process of cultural revival and economic development. Resulting from a diligent research in the areas of cultural anthropology, oral and documented history, the author presents relevant results in the field of linguistics, history and ethnography of the people udi.

Keywords: Ethnography; Azerbaijan; Udi-Albanians; Caucasian Albania; History; Linguistic; Nij; Christianity; Church history.

\section{Referências bibliográficas}

Aleksidze, Z.; Blair, B. The Albanian Script. The Process - How Its Secrets 4. Were Revealed. In: http://azer.com/aiweb/categories/ magazine/ai113_folder/ 113_articles/113_ zaza_aleksidze_secrets.html

Arutinov, A.A. 1905. Udiny [Os Udis]. Russkiy Antropologicheskiy Zhurnal. [Russian Anthropological Journal], Rossiya Sakt-Peterburg, 1-2: 93-94.

Bezhanov, M. 1892. Kratkiye svedeniya o Vartashene i ego zhitelyakh [Crônica de Vartashen e seus habitantes]. In: Smompk [Antologia de descrições de localidades e povos do Cáucaso], XIV: 213-262.

Claudii Ptolemaei. 1883. Geographia. Trad. Karl Müller. Paris: Didot.

Movsēs Dasxuranc'i. 1961. The History of the Caucasian Albanians. Trad. Charles J. F. Dowsett. London. Oriental Series. London: Oxford University Press.
Ganenkov, D; Lander, Y.; Maisak, T. 2010 From interrogatives to placeholders in Udi and Agul spontaneous narratives. In: Amiridze, N.; Davis, B.; Maclagan, M. (Eds.) Fillers in Discorse and Grammar. Philadelphia, John Benjamins Publishing Company: 95-118.

Ganenkov, D. 2008. Morfologicheskaya i semanticheskaya kharakteristika padezhey udinskogo jazyka. [Características morfológicas e semânticas dos casos Udi]. In: Alekseev, M.E.; Maisak, T.A.; Ganenkov, D.S.; Lander, Y.A. (Eds.) Udinskiy sbornik: grammatika, leksika, istoriya jazyka [Coleção Udi: gramática, vocabulário, história]. Mocow, Academia: 11-53.

Gukasyan, V. 1974. Udino-azerbaydzhansko-russkiy Slovar [Dicionário udi-azeri-russo] Baku: Publishing House "Elm".

Herodotus, 1987. The History. Trad. David Grene. Chicago: University of Chicago Press. 
Huseinov, R.A. 2008. Udin [Os Udis]. Irs magazine, 33 (3): 22-25.

Javadov, G.; Huseynov, R.A. 1999. Udi:Tarixi və etnoqrafik tadqiqat [A pesquisa histórica e etnográfica]. Baku: Publishing House "Elm".

Kechaari, G.A. 2001. Yanğın atrafinda raqs. Nümunalari Udi folkloru ["Dançando ao redor do fogo". Amostras de folclore udi]. Ganja: Publishing House "Agah".

Melikov, R.S. 2002. K problem proiskhozhdeniya i lokalizatsii plemeni utiev [Sobre o problema da origem e localização da tribo udi]. In: Mamedova, F.D. (Ed.) A Collection of Material from an International Conference on Caucasus Albania. Baku, Academy of Sciences of Azerbaijan "Azerneshr": 78-81.

Mobili, R.B. 2008. Etnografiya udin [Etnografia dos Udis]. Irs magazine, 33 (3): 26-29

Pliny the elder. 1855. The Natural History. Trad. Henry Thomas Riley. London: Henry George Bohn (publisher).

Strabo. 1924. The Geography. Trad. Horace Leonard Jones. The Loeb Classical Library Edition. Cambridge: Harvard University Press. 
